\title{
ГЛОБАЛЬНАЯ ПЕРСОНА
}

\section{У ИСТОКОВ ОТЕЧЕСТВЕННОЙ ГЛОБАЛИСТИКИ (К 85-летию А. Д. Урсула)}

\author{
Ильин И. В., Урсул Т. А., Чумаков А. Н.
}

Статья посвящена памяти недавно ушедшего от нас выдающегося философа и одного из основателей и ярких представителей современной глобалистики А. Д. Урсула. Авторы постарались отразить своеобразный, весьма насыщенный неожиданными поворотами жизненный путь ученого и то, как его взгляды вполне закономерно эволючионировали от увлеченности проблемами авиации и освоения космоса до методологических аспектов теории информации и теоретических основ глобальных исследований. Эти трансформации в судьбе одного человека представлены в контексте анализа основных черт и особенностей той эпохи, когда шло становление новой междисциплинарной области научного знания - глобалистики - и ее философского базиса. Особое внимание уделено отдельным работам и ключевым новаторским идеям А. Д. Урсула в области глобального эволючионизма, взаимодействия природы и общества, научно-технического прогресса, экологического образования и т. $n$. Показана его особая роль в осмыслении и поиске путей реализации на планетарном и национальном уровнях таких общезначимых концепций, как учение о ноосфере и устойчивое развитие. В заключительной части статьи говорится о плодотворной работе философа в последние годы на факультете глобальных процессов МГУ и о его особой роли в научно-педагогической жизни университета, а также в создании российских и международных общественных научно-исследовательских объединений.

Ключевые слова: А. Д. Урсул, философия, глобалистика, устойчивое развитие, ноосфера, концепичя, информатика, космос, глобальные исследования.

The article is dedicated to the memory of Arkady D. Ursul, an outstanding philosopher and one of the founders and prominent representatives of modern global studies, who has recently passed away. The authors show his peculiar, very full of unexpected turns life path and the way his views quite naturally evolved from a passion for aviation and space exploration to methodological aspects of information theory and theoretical foundations of global research. These transfor-

* Ильин Илья Вячеславович - д. полит. н., профессор, декан факультета глобальных процессов МГУ имени М. В. Ломоносова. E-mail: dekanat@fgp.msu.ru.

Урсул Татьяна Альбертовна - д. ф. н., профессор, заведующая кафедрой социальных наук и технологий Национального исследовательского технологического университета «Московский институт стали и сплавов». E-mail: ursult@mail.ru.

Чумаков Александр Николаевич - д. ф. н., профессор факультета глобальных процессов МГУ имени М. В. Ломоносова. E-mail: chumakov5@yandex.ru. 
mations in the fate of one person are presented in the context of the analysis of the main features and characteristics of the era when a new interdisciplinary field of scientific knowledge - globalistics - and its philosophical basis were taking shape. Special attention is paid to selected works and key innovative ideas of A. D. Ursul in the field of global evolutionism, interaction between nature and society, scientific and technological progress, environmental education, etc. His special role in comprehending and searching for ways to implement at the planetary and national levels such universally significant concepts as the doctrine of noosphere and sustainable development is shown. The final part of the article shows the results of the philosopher's fruitful work in recent years at the Department of Global Processes of Moscow State University and his special role in the scientific and pedagogical life of the university, as well as in the creation of Russian and international public research associations.

Keywords: A. D. Ursul, philosophy, globalistics, sustainable development, noosphere, concept, computer science, space, global studies.

28 июля 2021 г. исполнилось бы 85 лет выдающемуся ученому, одному из основателей и наиболее ярких представителей отечественной глобалистики, академику АН Молдовы, доктору философских наук, профессору факультета глобальных процессов МГУ Аркадию Дмитриевичу Урсулу. Меньше года он не дожил до своего юбилея и, если бы не коронавирус, его обширное творческое наследие, несомненно, пополнилось бы еще многими философскими исследованиями и интересными публикациями. Прежде всего это касается философской глобалистики, где он достиг выдающихся результатов.

В философию Аркадий Дмитриевич пришел не случайно, как не случайно сложились и его вполне определенные интересы в этой области. Он окончил Московский авиационный институт и после защиты в 1964 г. кандидатской диссертации по проблемам освоения космоса работал доцентом. В 1969 г. защитил докторскую диссертацию по методологическим проблемам теории информации и стал заведующим отделом философии естествознания в Институте философии АН СССР. В 1982-1988 гг. был приглашен на работу в Президиум АН Молдавской ССР, где стал вице-президентом и заведующим отделом философии и права. В 1988 г. перешел на должность директора Института социальной информатики Академии общественных наук, а в 1991 г. стал директором Ноосферно-экологического института Российской академии управления. С 1994 г. заведовал кафедрой социальной экологии Российской академии государственной службы при Президенте РФ. В последние годы жизни был директором Центра глобальных исследований и профессором факультета глобальных процессов МГУ имени М. В. Ломоносова.

А. Д. Урсул получил широкую известность как выдающийся философ и видный представитель современной российской науки, а также как талантливый педагог, воспитавший множество отечественных специалистов в области философской глобалистики, социальной экологии и устойчивого развития. Он оставил после себя оригинальное и богатое творческое наследие, состоящее из почти 1400 научных публикаций. В их числе более 250 монографий, книг и брошюр, а также вышедших под его редакцией более 250 научных сборников, коллективных трудов и статей в периодических изданиях, опубликованных в отечественных 
и зарубежных издательствах ${ }^{1}$. Им создано несколько научных школ по ряду направлений, подготовлено значительное число научных и педагогических кадров (он был научным руководителем более 100 кандидатов наук и научным консультантом 33 докторов философских наук). В течение десяти лет работал научным экспертом Экспертного совета ВАК РФ по философии, социологии и культурологии, в течение нескольких десятков лет возглавлял диссертационный совет по защите диссертаций на соискание ученой степени доктора наук по философии науки и техники.

Таким образом, являясь одним из наиболее ярких представителей отечественной глобалистики ${ }^{2}$, Аркадий Дмитриевич внес свой особый вклад в становление и развитие этого нового междисциплинарного научного направления. При этом он имел неоспоримое преимущество в решении философских проблем глобалистики, так как, с одной стороны, опирался на естественно-научную базу своего первоначального образования, а с другой стороны, его интересы в области исследования космоса и теории информации как нельзя лучше способствовали пониманию сущности глобальных процессов и использованию системного подхода в их исследовании. Важное значение имело и то, что к 60-м гг. прошлого века, то есть к тому времени, когда А. Д. Урсул, серьезно занявшись философией, обратился к глобальной проблематике, в этой области уже имелся определенный теоретический задел, который позволил целой плеяде отечественных ученых достаточно быстро сформировать главные контуры отечественной глобалистики и заложить основы ее наиболее важных направлений.

Одним из таких наиболее значимых направлений стала, несомненно, философская глобалистика, поскольку появилась серия принципиальных задач, решить которые без применения философии не представлялось возможным. В частности,

${ }^{1}$ В числе его основных публикаций такие монографии, как: Освоение космоса (1967); Природа информации (1968); Отражение и информация (1973); Человечество, Земля, Вселенная (1977); Философия и интегративно-общенаучные процессы (1981); Перспективы экоразвития (1990); Путь в ноосферу (1993); Экологическая проблема и агроноосферная революция; Переход России к устойчивому развитию. Ноосферная стратегия (1998); Устойчивое развитие (2000); Безопасность и устойчивое развитие (2001); Концептуальные основы устойчивого развития (2003); Устойчивое будущее (глобализация, безопасность, ноосферогенез) (2006); Универсальный эволюционизм (2007); Глобализация и переход к устойчивому развитию (2008); Глобальный эволюционизм (2010); Ильин И. В., Урсул А. Д. Глобальные исследования и эволюционный подход (2013); Ильин И. В., Урсул А. Д. Образование, общество, природа. Эволюционный подход и глобальные перспективы (2016).

${ }^{2}$ См.: Урсул А. Д. // Философы России XIX-XX столетий: Биографии, идеи, труды. Энциклопедический словарь / под ред. П. В. Алексеева. 3-е изд. М.: Академический Проект, 1999; Урсул А. Д. // Философы России начала XXI века. Биографии, идеи, труды. Энциклопедический словарь / под ред. П. В. Алексеева. М.: РОСПЭН, 2009; Урсул А. Д. / А. И. Мелуа // Российская академия естественных наук. СПб., 2001; Урсул А. Д. // 10 лет на службе России. Памятное издание к десятилетию Российской академии государственной службы при Президенте РФ / под ред. В. К. Егорова. М.: РАГС, 2004; Урсул А. Д. // Кто есть кто в экономике природопользования (Экономика природопользования: события и люди) / под ред. Н. Н. Лукьянчикова. М., 2009; Урсул А. Д. // Who is who в России. Zug. : Verlag Hübners, 2007; 2011; Ursul A. D. // Academia de Stiinte a Repulicii Moldova (50). Chisinau, 1996; Ursul A. D. // Membrii Academiei de Stiinte a Moldovei. Dictionar 1961-2006. Chisinau : Stiinta, 2006; Цырдя Т. Н. К 75-летию академика АН Республики Молдова А. Д. Урсула. Творческая биография // Strategia supravituirii din perspectiva bioeticii, filosofiei si medicine. Chisinau, 2011. 
требовалось разработать методологию междисциплинарных исследований, используя набиравший популярность системный подход; необходимо было исследовать исторические этапы и современный характер взаимодействия природы и общества в условиях нарастания экологического кризиса; следовало определить критерии глобальных проблем современности и дать им классификацию; нужно было также предложить общий язык междисциплинарного взаимодействия, сформировав категориальный аппарат нового научного направления. Наконец, требовалось исследовать научно-технические возможности и биосоциальные способности человека справляться с новыми вызовами, а также важно было определить перспективы их преодоления и сделать все это достоянием широкого общественного сознания.

Одних гуманитарных, а тем более сугубо философских подходов для решения такого сложного комплекса задач было явно недостаточно. Здесь требовались не только философская аналитика и широта мышления, но и определенная комбинация философского мышления с профессиональным владением конкретным материалом в той или иной области научного знания. Вот почему среди более полутора десятков тысяч ученых, занятых тогда в сфере философии (а это были преподаватели вузов, сотрудники академических институтов, издательских, общественных и государственных структур), нашлось совсем немного тех, кто на серьезном уровне и постоянной основе погрузился в область философской глобалистики.

И вот теперь, полвека спустя, становится хорошо видно, что наибольшие результаты и яркий след в глобалистике оставили именно такие философы, как И. Т. Фролов, получивший наряду с философским образованием специальную подготовку на биологическом факультете МГУ; А. Д. Урсул, пришедший в философию после окончания авиационного института; Р. С. Карпинская, имевшая два диплома об окончании философского и биологического факультетов МГУ; В. А. Лось, химик по первому базовому образованию; А. А. Горелов, окончивший геологический факультет МГУ; И. Ф. Кефели, посвятивший себя философии после обучения в политехническом институте; В. А. Кобылянский, поступивший в аспирантуру философского факультета после окончания географического факультета МГУ; А. В. Кацура, окончивший физфак МГУ и перешедший на работу в Институт философии АН СССР; Н. М. Мамедов, обучавшийся в аспирантуре Института философии АН СССР после окончания политехнического института; Д. М. Гвишиани, В. В. Загладин, Э. С. Маркарян - выпускники Московского государственного института международных отношений - и другие, также ставшие докторами философских наук, имея первоначальное нефилософское образование [Глобалистика... 2016].

С другой стороны, философская глобалистика обогатилась солидным теоретическим материалом за счет оригинальных идей и творческого вклада в нее таких выдающихся и философски мысливших представителей естествознания, а также точных и общественных наук, как Н. Н. Моисеев, Н. Н. Иноземцев, А. А. Громыко, А. В. Виноградов, Н. Ф. Реймерс, Г. В. Добровольский, М. И. Будыко, А. Л. Яншин, С. П. Капица, Ю. А. Израэль, И. В. Бестужев-Лада, О. С. Колбасов, Г. С. Хозин, В. И. Данилов-Данильян и др. [Там же].

Суммируя вышеизложенное, можно сказать, что в истории мировой философии, равно как и в отечественной философской мысли, $\mathrm{XX}$ век явно выделяется 
уже тем, что именно в этом столетии в философии появилась еще одна, принципиально новая, никогда прежде не существовавшая тема познания - планета Земля как единая целостная система во всех аспектах ее проявления. По существу, именно это имел в виду и А. Д. Урсул, когда писал, что «становление глобального эволюционизма - один из примеров того, что в настоящее время, а не только в далеком прошлом, философия порождает новые области уже не только частнонаучного, но и междисциплинарно-общенаучного знания» [Урсул 2015]. Иными словами, в двадцатом столетии пристального философского внимания к себе потребовал глобус как уникальное космическое тело и уникальная система, где в неживой, живой и социальной сферах протекают различные глобальные процессы. Один из них, порожденный общественными отношениями, получил название глобализация [Новая... 2000: 533-534; Глобалистика... 2003: 181-199; Чумаков 2011: 174-180].

В этой связи следует подчеркнуть, что в качестве целостной системы мировое сообщество формировалось постепенно в результате своего поступательного интенсивного и экстенсивного развития. Однако только с эпохи Великих географических открытий эти процессы реально обрели планетарное измерение. Заметим при этом, что осознание данного факта пришло не сразу. По существу глобальными категориями стали мыслить с конца XVIII - начала XIX в., что хорошо просматривается в высказываниях И. Канта, Т. Мальтуса, К. Маркса, Ф. Энгельса, Н. Я. Данилевского, О. Шпенглера. Но в полном смысле этого слова глобальный мир и мировое сообщество стали предметом особого внимания и специального анализа только в XX в. [Anheier, Juergensmeyer 2012].

Такие мыслители, как А. Тойнби, П. Тейяр де Шарден, В. И. Вернадский, К. Ясперс, Б. Рассел, А. Эйнштейн и др., несомненно, были теми, кто прямо или косвенно, в том числе и с философских позиций, теоретизировал и развивал свои идеи в глобальном контексте [Global... 2017]. Именно они еще в первой половине $\mathrm{XX}$ столетия сделали предметом особого внимания человечество как единое целое и стали рассматривать его как составную и неотъемлемую часть естественной природы. Для них переход от раздробленности, разобщенности и фрагментарности в мировом сообществе к единству, целостности и глобальной взаимозависимости планетарного человечества уже тогда был вполне осознаваемым фактом. Так, например, $A$. Тойнби, рассматривавший общественное развитие как последовательную смену различных цивилизаций, сделал вывод, что в XX в. началась всеобщая всемирная история. Тем самым подчеркивалось, что кардинальные перемены затронули не только основы общественного устройства, но и главные тенденции мировых социальных процессов.

На уникальность человека в качестве составной части биосферы одним из первых обратил внимание П. Тейяр де Шарден, который развивал концепцию гармонизации отношений человека с природой, призывая к отказу от эгоистических устремлений во имя объединения всего человечества. «Выход для мира, двери для будущего, вход в сверхчеловечество, - говорил он, - открываются вперед, и не для нескольких привилегированных лиц, не для одного избранного народа! Они откроются лишь под напором всех вместе и в том направлении, в котором все вместе могут соединиться и завершить себя в духовном обновлении Земли» [Тейяр де Шарден 1987: 194]. 
Еще более высокий уровень философского осмысления взаимодействия природы и общества представлен в работах $B$. И. Вернадского, концепция ноосферы которого уже с самого начала могла бы стать по существу манифестом гармоничного развития планетарных социоприродных процессов [Вернадский 1988]. Однако идеи В. И. Вернадского опережали свое время и оставались без должного внимания более трех десятилетий, пока не обрели новое дыхание в начале 1970-х гг. Они оказались востребованными в контексте развития идей философской глобалистики, когда резко обострились экологические проблемы и начались активные поиски оптимизации взаимодействия природы и общества.

О сущности глобального мира с позиции философии рассуждал и $K$. Ясnеpc, который еще в 1948 г. писал: «Наша исторически новая ситуация, впервые имеющая решающее значение, являет собой реальное единство людей на Земле. Благодаря техническим возможностям современных средств сообщения, наша планета стала единой целостностью, полностью доступной человеку, стала "меньше", чем была некогда Римская империя... Теперь проблемой и задачей стал мир в целом. Тем самым происходит полное преобразование истории. Решающим является теперь следующее: нет ничего, что находилось бы вне сферы происходящих событий. Мир замкнулся. Земной шар стал единым. Обнаруживаются новые опасности и возможности. Все существенные проблемы стали мировыми проблемами, ситуация - ситуацией всего человечества» [Ясперс 1991: 141].

Таким образом, в среде философов и ученых уже в первой половине XX в. возникло понимание не только того, что наступает новая эпоха - эпоха планетарных явлений, но и того, что в этих новых условиях люди могут и должны противостоять природной и социальной стихии только сообща. При этом ориентация на покорение природы и интенсивное потребление природных ресурсов все больше стала меняться в пользу их рационального использования и пропаганды природоохранной деятельности.

Дальнейший этап в осмыслении глобальных процессов во многом был связан с деятельностью созданного в 1968 г. Римского клуба и публикацией его докладов, которые раскрыли многие аспекты глобальных проблем, показали угрозы, которые они несут мировому сообществу, и тем самым привлекли к ним пристальное внимание не только ученых и философов, но и политиков, общественных деятелей, а также широких слоев населения во всем мире ${ }^{3}$.

Что касается нашей страны, то, как уже отмечалось, активные исследования глобальных проблем начались здесь примерно в то же время - на рубеже 1960-х 1970-х гг. А ключевую роль при этом сыграли именно философы и авторитетные ученые страны, объединившиеся первоначально вокруг журнала «Вопросы философии», главным редактором которого тогда был И. Т. Фролов. В инициированной им специальной рубрике журнала «Глобальные проблемы современности: социально-философские и методологические аспекты» наряду со статьями фило-

${ }^{3}$ См.: Club of Rome // Global Studies Encyclopedic Dictionary / ed. by A. N. Chumakov, I. I. Mazour, W. C. Gay. With a Foreword by Mikhail Gorbachev. Amsterdam; New York, NY: Editions Rodopi B. V., 2014; Meadows D. H, Meadows D. L, Randers J., Behrens III W. W. The Limits to Growth; A Report for the Club of Rome's Project on the Predicament of Mankind. New York : Universe Books, 2017; Mesarovic M., Pestel E. Mankind at the Turning Point, Duttion. New York, 1974; Laszlo E. Goals for Mankind. New York : Dutton, 1977; et al. 
софов И. Т. Фролова, А. Д. Урсула, Б. Ц. Урланиса, В. В. Загладина, Г. С. Гудожника, В. А. Лося публиковались статьи таких известных ученых, как П. Л. Капица, Н. Н. Моисеев, В. А. Энгельгардт, Д. М. Гвишиани, И. И. Герасимов и др. А с 1980 г., когда И. Т. Фролов стал председателем Научного совета при Президиуме АН СССР по комплексной проблеме «Философские и социальные проблемы науки и техники», эта структура стала основным центром в организации и проведении глобальных исследований в нашей стране.

Это было время, когда наряду с сугубо академическими исследованиями глобальной проблематики и все более активным включением в них ученых и специалистов различных профилей появлялись и множились общественные движения и организации экологической, природоохранной, антивоенной, научно-технической и т. п. направленности. Именно в это время в полную силу проявился творческий потенциал и организационный талант А. Д. Урсула, который в 1975 г. стал членом Международного общества «Человек и космос». В 1991 г. он основал Международную академию устойчивого развития (ноосферы) и стал ее президентом. В этом же году А. Д. Урсул основал Российскую академию космонавтики им. К. Э. Циолковского и был избран ее почетным президентом. Он стоял у истоков создания и Российской экологической академии (1992), и Международной академии информатизации (1992), и Международной академии информационных процессов и технологий (1993). Наряду с этим А. Д. Урсул был членом редколлегий и редакционных советов многих журналов и периодических изданий, таких, например, как «Век глобализации», «Вестник МГУ. Серия глобалистики и геополитики», «Земля и Вселенная», «Научно-техническая информация», «Журнал АН Молдавии по философии, социологии и политологии», «Вестник Российского торговоэкономического университета», «Вестник КемГУКИ», «Кавказские научные записки», «International Journal E\&M Euroeducation» и др.

Все это представляет А. Д. Урсула одним из наиболее продуктивных ученых и эффективных организаторов науки в области глобальных проблем и процессов, которые он исследовал в методологическом аспекте, во взаимосвязи общественных, естественных, технических и других наук. Отмечая новаторский характер и особую роль Аркадия Дмитриевича уже на первоначальном этапе становления глобалистики, один из видных представителей первой волны данного научного направления А. В. Кацура отмечает, что в этой связи следовало бы принять во внимание атмосферу 1960-х гг. «Еще не утихли бои с ретроградами, сторонниками бичующей фразы “кибернетика - буржуазная лженаука", - говорит он. А ведь именно кибернетика, стремительно ворвавшаяся в середине века в круг научного знания, заставила по-новому оценить глубину, мощь и универсализм, казалось бы, давно знакомого понятия “информация". Еще не успел возникнуть мем “информационное общество”, а А. Д. Урсул был здесь одним из смелых первопроходцев (наряду со старшими коллегами, замечательными учеными И. Б. Новиком, Л. Б. Баженовым, В. И. Тюхтиным...). И это оказалось очень нужным для развития отечественной философии науки. Как, впрочем, и интересные, во многом пионерские размышления Аркадия Дмитриевича о философии космонавтики, еще одной новой и бурно растущей области науки, инженерии и орбитальной практики» [Кацура 2020]. 
Таким образом, уже с начала 1970-х гг. А. Д. Урсул исследовал одну из наиболее актуальных глобальных проблем того времени - проблему освоения космоса. В ходе этих теоретических изысканий им было выдвинуто и обосновано то направление глобальных исследований, которое позже получило наименование космоглобалистики (сам же термин был предложен им в начале 1990-х гг.) [Глобальные... 1988]. В этом же ряду стоит и его концепция антропогеокосмизма (социогеокосмизма), согласно которой развитие космонавтики является приоритетной задачей для решения земных, общепланетарных проблем человечества и формирования единой суперсистемы «человечество - Земля - Вселенная», ставшей методологической основой космоглобалистики.

В своей монографии, посвященной философским проблемам космонавтики, А. Д. Урсул при рассмотрении вопроса о становлении человечества как целостной цивилизации, которая наиболее эффективно сможет взаимодействовать с природой планеты и космоса, выделил два основных аспекта этого единства (целостности) человечества [Урсул 1977]. Первый аспект связан с системно-историческими, пространственными характеристиками (глобальными и космическими). Второй аспект касается общих закономерностей, которые позволяют говорить об определенном единстве человечества задолго до появления устойчивых связей между ранее автономно развивавшимися цивилизациями землян. Учитывая, что проблема формирования целостности человечества составляет суть и историческую «цель» процесса глобализации, речь в данном случае идет о критериях глобальности и об их космических трансформациях.

В монографии «Проблема внеземных цивилизаций. Философско-методологические аспекты» была выдвинута и обоснована идея, согласно которой одной из наиболее важных задач проблемы поиска внеземных цивилизаций является содействие развитию наук и земных проблем человечества (прежде всего глобальных), требующих подхода к нашей цивилизации как к системно-целостному прогрессивно развивающемуся объекту [Рубцов, Урсул 1984]. А в опубликованной в 1981 г. монографии «Философия и интегративно-общенаучные процессы» А. Д. Урсул, по-видимому, впервые употребил термин «глобализация» и обосновал интегративно-общенаучный характер глобальных проблем [Урсул 1981: 204].

Широко известны работы А. Д. Урсула по проблемам информации, в которых обосновывается глобальный характер этого понятия, в частности, он говорит о становлении глобального информационного общества и формулирует информационный критерий развития, который используется в глобальных исследованиях. В этой связи он предложил в качестве особого направления глобалистики информащионную глобалистику, акцентирующую внимание на информационном ракурсе глобальных процессов и систем. Это направление включает в себя исследование проблемы информации как глобальной проблемы, информационную глобализацию и другие формы использования информационного подхода к изучению глобальных социальных, социоприродных и природных глобальных процессов и систем.

В серии монографических трудов А. Д. Урсула обсуждается междисциплинарная концепция глобального социоприродного перехода к устойчивому развитию. При этом под устойчивым развитием понимается, как правило, «управляемое системно-сбалансированное социоприродное развитие, не разрушающее 
окружающую природную среду и обеспечивающее выживание и безопасное неопределенно долгое существование цивилизации» [Ильин и др. 2015: 13]. В этой связи им была предложена и разработана концепция права устойчивого развития как наиболее вероятного варианта перехода от современного международного права к будущему глобальному праву, имеющему принципиально инновационноопережающий характер.

Знаковой для понимания творчества А. Д. Урсула является монография «Путь в ноосферу. Концепция выживания и устойчивого развития цивилизации» [Урсул 1993]. Здесь впервые в отечественной литературе было показано, что решение всего комплекса глобальных проблем лежит на пути планетарного перехода к устойчивому развитию, а становление ноосферы как глобального (а в перспективе и планетарно-космического) процесса будет вначале реализовываться через устойчивое развитие. В этом контексте ноосферогенез рассматривался автором монографии с социотехнологической точки зрения как созидание вначале глобального информационного общества с устойчивым развитием (инфоноосферы), затем как становление экологического общества (эконоосферы) в планетарном масштабе, а в отдаленной перспективе - космоноосферы. В этой публикации были сформулированы также основные принципы нового этапа глобального процесса становления сферы разума (как формирования опережающего ноосферного интеллекта), реализуемой через глобальный процесс устойчивого развития, что положило начало «неклассическому этапу» учения о ноосфере - ноосферологии. В этом контексте важно подчеркнуть, что, по мнению Аркадия Дмитриевича, уже само название «ноосфера» выдвигает на первый план «не материальный компонент интеллекта, а духовно-идеальные процессы и факторы. Вполне понятно, - говорил он, - что идеальное не может существовать без материального, и ноосфера видится как “синкретическое” материально-идеальное образование, но главенствующим активным актором и фактором выступает ноосферный интеллект» [Его же 2015: 9].

Особое внимание А. Д. Урсул уделял и социоприродным глобальным процессам, в частности, их социоэкологическим аспектам, применяя к их исследованию эволюционный и футурологический подходы; при этом акцентировал внимание на особенностях планетарного экоразвития в аспекте перехода к устойчивому будущему. «Будущие поколения землян, - писал он, - уже будут жить в нелинейном глобально-ограниченном мире, и им придется соединять не только экономику и экологию. Придется создавать иную - не просто и не только “зеленую” экономику, - а альтернативную нелинейную интенсивную хозяйственную деятельность...» [Там же: 101]. Он также говорил об агроноосферной революции, которая рассматривалась им как принципиально новый глобальный процесс, в перспективе гарантирующий обеспечение продовольственной безопасности цивилизации.

Изучая проблемы образования в условиях глобального мира, А. Д. Урсул разработал основные принципы образования для устойчивого развития и сформулировал концепцию опережающего образования, тесно связанную с экологизацией и информатизацией общества. Он говорил о возможности и необходимости кардинальных трансформаций современного образования, вектор которых направлен от современной индустриальной и постиндустриальной его форм к образованию для устойчивого развития, а в дальнейшем - к ноосферному образованию. Он 
разработал концепцию глобально-эволюционного образования как наиболее широкого информационного представления образовательного процесса, в котором образование видится сквозь призму универсального (глобального) эволюционизма уже в социоприродной системе «человек - общество - природа».

С начала 1970-х гг. значительное внимание А. Д. Урсула было посвящено исследованиям глобальной (универсальной) эволюции. Он рассматривал эту эволюцию как перманентную самоорганизацию во Вселенной и как ее социоприродное (планетарное и космическое) продолжение. В этой связи им были сформулированы общие и социоестественные принципы глобальной эволюции, дана информационно-синергетическая интерпретация антропного космологического принципа, введен принцип темпоральной целостности и футуризации для исследования социоприродной истории, исследованы перспективы социального бессмертия и постсоциального сценария глобальной эволюции.

В написанной совместно с И. В. Ильиным монографии «Эволюционная глобалистика (концепция эволюции глобальных процессов)» в дополнение к историческому подходу, ставшему уже традиционным в глобальных исследованиях, был предложен принципиально новый подход - эволючионный [Ильин, Урсул 2009]. Суть этого подхода заключается в том, что основным предметом глобальных исследований должны быть глобальные процессы, протекающие во всех сферах планеты (неживой, живой и социальной), и рассматриваться они должны в контексте их эволюции на планете. В итоге во временном аспекте выделяются следующие направления глобальных исследований: палеоглобалистика, современная глобалистика и футуроглобалистика. Последняя исследует такие глобальные процессы, как ноосферогенез и переход к устойчивому развитию. Заключительная глава этой монографии посвящена теме «От глобальных исследований к глобальному образованию», где проводится принципиальное различие между терминами «Глобализация образования» и «глобальное образование». В частности, подчеркивается, что глобализация образования относится больше к процессу обретения им целостности и в перспективе предполагает объединение национальных образовательных систем в единую мировую систему образования, тогда как глобальное образование характеризует качественно-содержательную трансформацию в образовательном процессе, «предметное поле которого наполняется глобальным знанием и мировоззрением, получаемым в результате глобальных исследований» [Там же: 150]. При этом особое внимание обращается на то, что «одна из наиболее определяющих особенностей новой модели глобального образования XXI в. ее нацеленность не просто на удовлетворение жизненных потребностей ныне живущих и будущих поколений, а на их возвышение, когда духовно-интеллектуальные потребности и интересы постепенно станут доминирующими» [Там же: 174]. Более основательно эти идеи были развиты затем в фундаментальной монографии «Образование, общество, природа: Эволюционный подход и глобальные перспективы» [Ильин, Урсул 2016].

Значительным является вклад А. Д. Урсула и в разработку идей обеспечения безопасности через реализацию концепции устойчивого развития, что стало по существу теоретическим обоснованием утвержденной в 2009 г. «Стратегии национальной безопасности Российской Федерации до 2020 г.», а также принятой в конце 2015 г. «Стратегии национальной безопасности Российской Федерации». 
Отдавая должное выдающемуся вкладу А. Д. Урсула в становление и развитие глобальных исследований и философской глобалистики, в частности, следует отметить, что его богатое и оригинальное творческое наследие оказалось весьма востребованным как в профессиональном сообществе, так и среди более широкой аудитории. Так, его идеи ноосферных оснований глобалистики, ранжирование приоритетов стратегии безопасности государств, теоретические основы и пути реализации ноосферных идей, концепции устойчивого развития и т. п. активно используются в учебном процессе на факультете глобальных процессов Московского государственного университета имени М. В. Ломоносова. Будучи с 2013 г. ведущим профессором этого факультета, он организовал здесь Центр глобальных исследований, читал авторские курсы по глобальным исследованиям для студентов и аспирантов, руководил их квалификационными работами; входил в Государственную экзаменационную комиссию и Ученый совет факультета. А. Д. Урсул активно участвовал в организации и проведении масштабных Международных научных конгрессов по глобалистике, периодически проводимых на базе факультета глобальных процессов МГУ. Он также стоял у истоков создания Международной академии глобальных исследований (МАГИ) и Российского общества глобальных исследований (РОГИС), объединивших научный потенциал и расширивших связи МГУ с другими российскими и зарубежными вузами, структурами и общественными организациями, работающими в области глобалистики.

\section{Лuтература}

Вернадский В. И. Философские мысли натуралиста. М. : Наука, 1988.

Глобалистика. Персоналии, организации, труды. Энциклопедический справочник / гл. ред., сост. И. В. Ильин, И. И. Мазур, А. Н. Чумаков. М. : Кнорус, 2016.

Глобалистика: Энциклопедия / гл. ред. И. И. Мазур, А. Н. Чумаков. М. : Радуга, 2003.

Глобальные проблемы социального развития (философско-методологические аспекты) / отв. ред. А. Д. Урсул. Кишинев : Штиинца, 1988.

Ильин И. В., Лось В. А., Урсул А. Д. Устойчивое развитие и глобальные процессы: учебник. М. : МГУ, 2015.

Ильин И. В., Урсул А. Д. Эволюционная глобалистика (концепция эволюции глобальных процессов). М. : Изд-во МГУ, 2009.

Ильин И. В., Урсул А. Д. Образование, общество, природа: Эволюционный подход и глобальные перспективы. М. : Изд-во МГУ, 2016.

Кацура А. В. Информация, ноосфера, планета. Памяти Аркадия Дмитриевича Урсула. 2020 [Электронный ресурc]. URL: https://www.globalistika.ru/post/информацияноосфера-планета (дата обращения: 10.06.2021).

Новая философская энциклопедия: в 4 т. / под. ред. В. С. Степина. Т. 1. М. : Мысль, 2000.

Рубцов В. В., Урсул А. Д. Проблема внеземных цивилизаций. Философско-методологические аспекты. Кишинев : Штиинца, 1984.

Тейяр де Шарден П. Феномен человека. М. : Наука, 1987.

Урсул А. Д. Человечество, Земля, Вселенная. Философские проблемы космонавтики. М. : Мысль, 1977. 
Урсул А. Д. Философия и интегративно-общенаучные процессы. М. : Наука, 1981.

Урсул А. Д. Путь в ноосферу. Концепция выживания и устойчивого развития цивилизации. М. : Луч, 1993.

Урсул А. Д. Феномен ноосферы: Глобальная эволюция и ноосферогенез. М. : ЛЕНАНД, 2015.

Чумаков А. Н. Культура и вызовы глобализации: новые подходы // Век глобализации. 2011. № 2(8). С. 174-180.

Ясперс К. Смысл и назначение истории. М. : Политиздат, 1991.

Anheier H. K., Juergensmeyer M. Encyclopedia of Global Studies. Thousand Oaks, CA : SAGE Publications, 2012.

Global Studies Directory. People, Organizations, Publications. Leiden; Boston : Brill, 2017.

\section{References}

Vernadskiy V. I. Filosofskiye mysli naturalista [Philosophical Thoughts of a Naturalist]. Moscow : Nauka, 1988.

Globalistika. Personalii, organizatsii, trudy. Entsiklopedicheskiy spravochnik [Globalistics. Personalities, Organizations, Works: encyclopedic reference] / ed. by I. V. Il'in, I. I. Mazur, A. N. Chumakov. Moscow : Knorus, 2016.

Globalistika: Entsiklopediya [Globalistics: Encyclopedia] / ed. by I. I. Mazur, A. N. Chumakov Moscow : Raduga, 2003.

Global'nyye problemy sotsial'nogo razvitiya (filosofsko-metodologicheskiye aspekty) [Global Problems of Social Development (Philosophical and Methodological Aspects)] / ed. by A. D. Ursul. Kishinev : Shtiintsa, 1988.

Il'in I. V., Los' V. A., Ursul A. D. Ustoychivoye razvitiye i global'nyye protsessy [Sustainable Development and Global Processes] : textbook. Moscow : MSU Press, 2015.

Il'in I. V., Ursul A. D. Evolyutsionnaya globalistika (kontseptsiya evolyutsii global'nykh protsessov) [Evolutionary Global Studies (The Concept of the Evolution of Global Processes)]. Moscow : MSU Press, 2009.

Il'in I. V., Ursul A. D. Obrazovaniye, obshchestvo, priroda: Evolyutsionnyy podkhod i global'nyye perspektivy [Education, Society, Nature: An Evolutionary Approach and Global Perspectives]. Moscow : MSU, 2016.

Katsura A. V. Informatsiya, noosfera, planeta. Pamyati Arkadiya Dmitriyevicha Ursula. 2020 [Information, Noosphere, Planet. In memory of Arkady Dmitrievich Ursul]. URL: https://www.globalistika.ru/post/informatsiya-noosfera-planeta (accessed: 10.06.2021).

Novaya filosofskaya entsiklopediya [New Philosophical Encyclopedia] : in 4 vols. / ed. by V. S. Stepin. Vol. 1. Moscow : Mysl', 2000.

Rubtsov V. V., Ursul A. D. Problema vnezemnykh tsivilizatsiy. Filosofsko-metodologicheskiye aspekty [The Problem of Extraterrestrial Civilizations. Philosophical and Methodological Aspects]. Kishinev : Shtiintsa, 1984.

Teilhard de Chardin P. Fenomen cheloveka [The Phenomenon of a Human]. Moscow : Nauka, 1987. 
Ursul A. D. Chelovechestvo, Zemlya, Vselennaya. Filosofskiye problemy kosmonavtiki [Humanity, Earth, Universe. Philosophical Problems of Cosmonautics]. Moscow: Mysl', 1977.

Ursul A. D. Filosofiya i integrativno-obshchenauchnyye protsessy [Philosophy and Integrative General Scientific Processes]. Moscow : Nauka, 1981.

Ursul A. D. Put' v noosferu. Kontseptsiya vyzhivaniya i ustoychivogo razvitiya tsivilizatsii [The Path to the Noosphere. The Concept of Survival and Sustainable Development of Civilization]. Moscow : Luch, 1993.

Ursul A. D. Fenomen noosfery: Global'naya evolyutsiya i noosferogenez [The Phenomenon of the Noosphere: Global Evolution and Noospherogenesis]. Moscow : LENAND, 2015.

Chumakov A. N. Kul'tura i vyzovy globalizatsii: novyye podkhody [Culture and Challenges of Globalization: New Approaches] // Vek globalizatsii. 2011. No. 2(8). Pp. 174-180.

Yaspers K. Smysl i naznacheniye istorii [Culture and Challenges of Globalization: New Approaches]. Moscow : Politizdat, 1991.

Anheier H. K., Juergensmeyer M. Encyclopedia of Global Studies. Thousand Oaks, CA : SAGE Publications, 2012.

Global Studies Directory. People, Organizations, Publications. Leiden; Boston : Brill, 2017. 